\title{
Navigated Placement of Two Odontoid Screws Using the O-Arm Navigation System: A Technical Case Report
}

\author{
Clara K. Starkweather ${ }^{1}$, Ramin Morshed ${ }^{1}$, Caleb Rutledge ${ }^{1}$, Phiroz Tarapore ${ }^{2,}, 3$ \\ 1. Neurological Surgery, University of California San Francisco, San Francisco, USA 2. Neurological Surgery, San \\ Francisco General Hospital, San Francisco, USA 3. Neurological Surgery, San Francisco Veteran's Hospital, San \\ Francisco, USA
}

Corresponding author: Caleb Rutledge, william.rutledge@ucsf.edu

\begin{abstract}
Odontoid fractures are common cervical spine fractures and lead to atlantoaxial instability depending on their type. Fractures through the base of the odontoid neck are considered for surgery. While the management of these fractures is controversial and may include external immobilization or posterior fusion, an odontoid screw offers the advantages of directly crossing the fracture site while preserving motion at C12. Although intraoperative navigation is routinely utilized in spine surgery, there are few reports of navigated anterior odontoid screw placement. In this report, we describe the safe and accurate placement of two anterior odontoid screws using the $\mathrm{O}$-arm navigation system in an octogenarian with a type II odontoid fracture. Details of the technical approach are also provided. The follow-up imaging at three months confirmed the healing of the fracture. Intraoperative navigation using the $\mathrm{O}$-arm system allows for safe and accurate placement of two odontoid screws.
\end{abstract}

Categories: Neurosurgery

Keywords: navigated screw placement, o-arm, odontoid screw

\section{Introduction}

Odontoid fractures are common cervical spine fractures, particularly among the elderly [1,2]. These fractures are classified according to the Anderson and D’Alonzo classification [3]. Type II fractures involving the base of the odontoid neck are the most common type and are considered unstable, usually requiring prolonged external immobilization or surgical fixation [1]. Fixation can be achieved via both anterior and posterior approaches, including anterior odontoid screw fixation [4]. Unlike a posterior C1-2 Harms fusion, an odontoid screw directly crosses the fracture site and preserves motion at C1-2. Accurate screw placement is essential to ensure adequate fracture reduction and prevent neurological complications, and biplanar fluoroscopy with two C-arms is usually required.

Received 07/19/2020

Review began 09/06/2020 Review ended 09/08/2020 Published 09/29/2020

○) Copyright 2020

Starkweather et al. This is an open access article distributed under the terms of the Creative Commons Attribution License CC-BY 4.0., which permits unrestricted use, distribution, and reproduction in any medium, provided the original author and source are credited.
Navigated screw placement increases the accuracy of screw placement in spine surgery $[5,6]$. However, there are few reports of navigated odontoid screw placement. Herein we report the navigated placement of two anterior odontoid screws using the $\mathrm{O}$-arm navigation system, which is a portable imaging device that encircles the patient and works similar to a CT scanner to generate three-dimensional images intraoperatively. In this report, the $\mathrm{O}$-arm navigation was used in an octogenarian with a type II odontoid fracture.

\section{Case Presentation}

An 86-year-old male presented after a motor vehicle accident with a well-corticated, chronic-appearing Jefferson fracture, and an acute type II odontoid fracture with fracture geometry suitable for odontoid screw reduction (Figure 1). 


\section{Cureus}
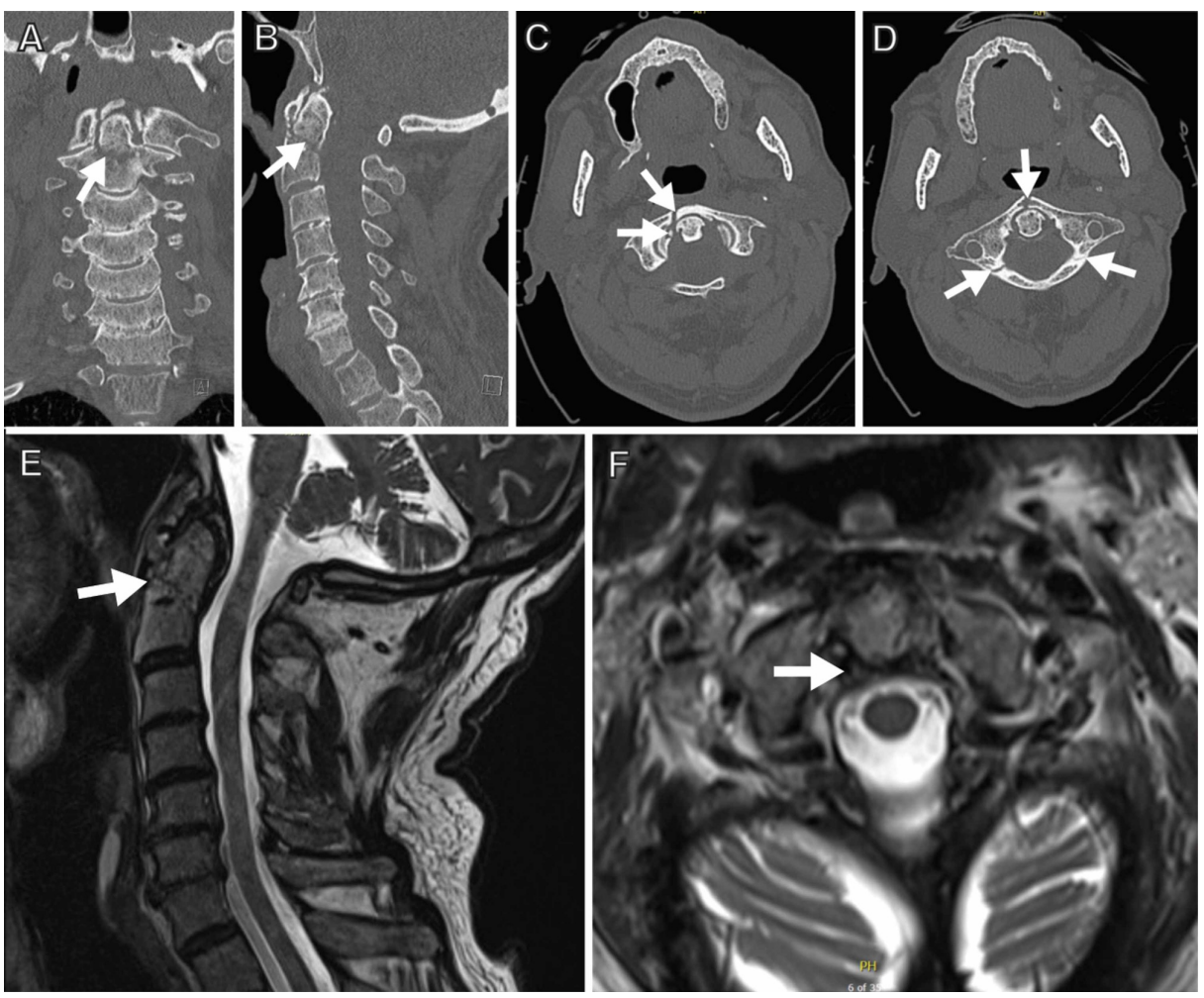

\section{FIGURE 1: Preoperative images}

(A, B) coronal (A) and sagittal (B) CT views of the cervical spine demonstrate a type Il odontoid fracture. (C, D) axial views demonstrate a chronic-appearing Jefferson fracture (chronic Jefferson fracture indicated by arrows). (E, F) T2-weighted MRI sagittal (E) and axial (F) images demonstrate the odontoid fracture (arrow in $\mathrm{E})$ and an intact transverse ligament (arrow in F)

CT: computed tomography; MRI: magnetic resonance imaging

He was brought to the operating room and placed in a supine position on a regular bed. A Mayfield skull clamp was applied, and a large wad of cotton was placed in the mouth. The Medtronic arm and frame (Medtronic, Dublin, Ireland) were attached to the Mayfield clamp. The O-arm was used to obtain anteroposterior (AP) and lateral X-rays. After positioning, the patient was then prepped and draped in a sterile fashion (set-up displayed in Figure 2A), and the anterior surface of the vertebral bodies was exposed using a transverse skin incision at the C5-6 level. A combination of Metzenbaum scissors, bipolar cautery, and blunt dissection was used to expose the spine, similar to an anterior cervical discectomy and fusion approach. An Apfelbaum retractor system (Aesculap, Center Valley, PA) was used to retract soft tissue. AP and lateral X-rays were obtained to confirm the appropriate level, and a full O-arm spin was obtained (Figure $2 B$ ). Part of the C2-3 disk was removed to avoid anterior placement of the screw and compromise of the anterior cortex of C2. A handheld Stealth probe, which allows intraoperative navigation based on imaging, was then registered and used to determine an appropriate starting point and trajectory for the first odontoid screw (Figure 2C). 


\section{Cureus}
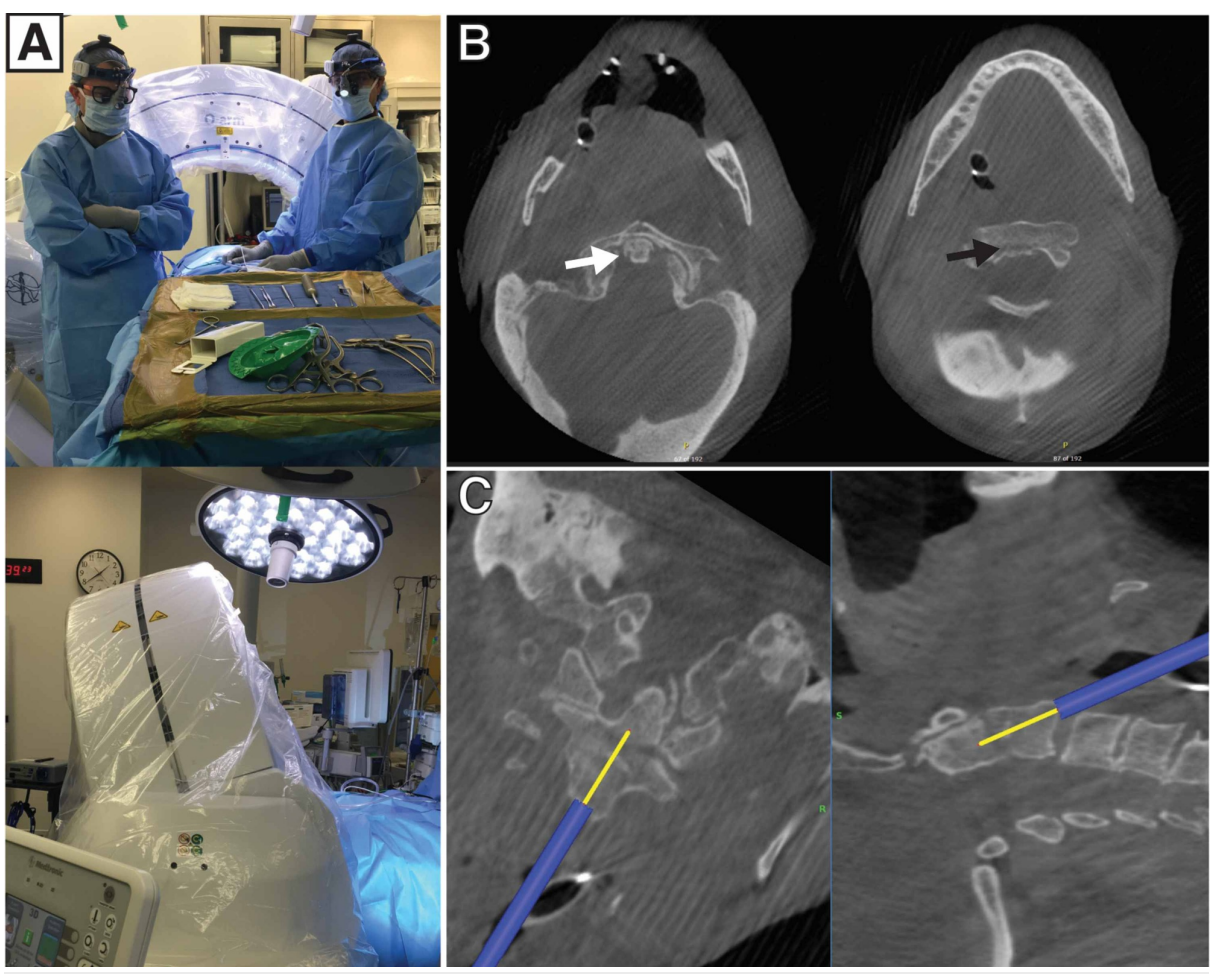

FIGURE 2: An intraoperative CT provides a real-time view of the fracture and spinal alignment after the patient positioning. The $C T$ is then used to plan and navigate screw placement

(A) O-arm set-up. (B) axial images demonstrating intraoperative visualization of the tip of the dens and C2 body, indicated by white and black arrows respectively, prior to screw placement. (C) visualization of screw trajectory

CT: computed tomography

Fluoroscopy images of the following steps are displayed in Figure 3.

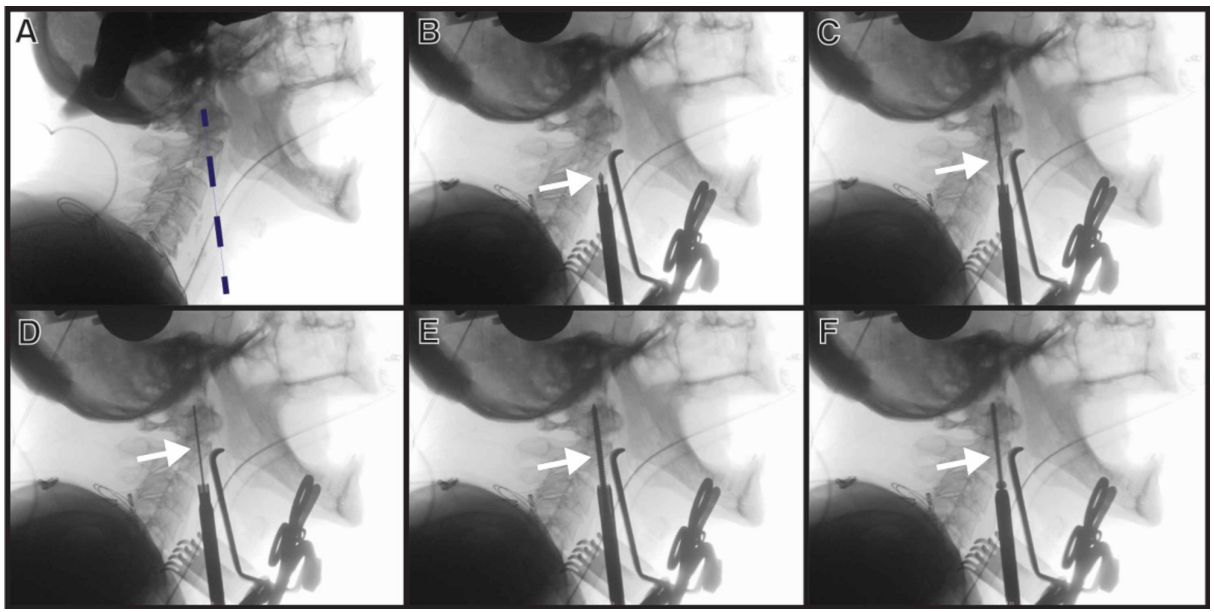

FIGURE 3: Planned trajectory of odontoid screw placement

X-rays from the O-arm are used to (A) confirm planned trajectory (dotted line), (B) confirm drill position (drill tip indicated with the arrow), (C, D) visualize tapping (tap indicated with the arrow), and (E, F) visualize screw placement (screw indicated with the arrow). This eliminates the need for biplanar fluoroscopy and two C-arms

A pneumatic drill was used to create a pilot hole in the inferior aspect of $\mathrm{C} 2$. A drill guide registered to the Stealth system was then placed in the pilot hole, and a drill also registered to the Stealth system was used to 


\section{Cureus}

drill through the $\mathrm{C} 2$ body across the fracture line toward the odontoid tip. AP and lateral X-rays were obtained to confirm the screw trajectory. The trajectory was tapped over a K-wire. After tapping, a screw was inserted under AP and lateral fluoroscopic guidance. The screw length was obtained from measurements from the O-arm-generated CT. A second trajectory was then planned and an additional odontoid screw was placed. A final $\mathrm{O}$-arm spin was obtained to confirm the placement of the two screws and adequate reduction of the fracture (Figure 4).
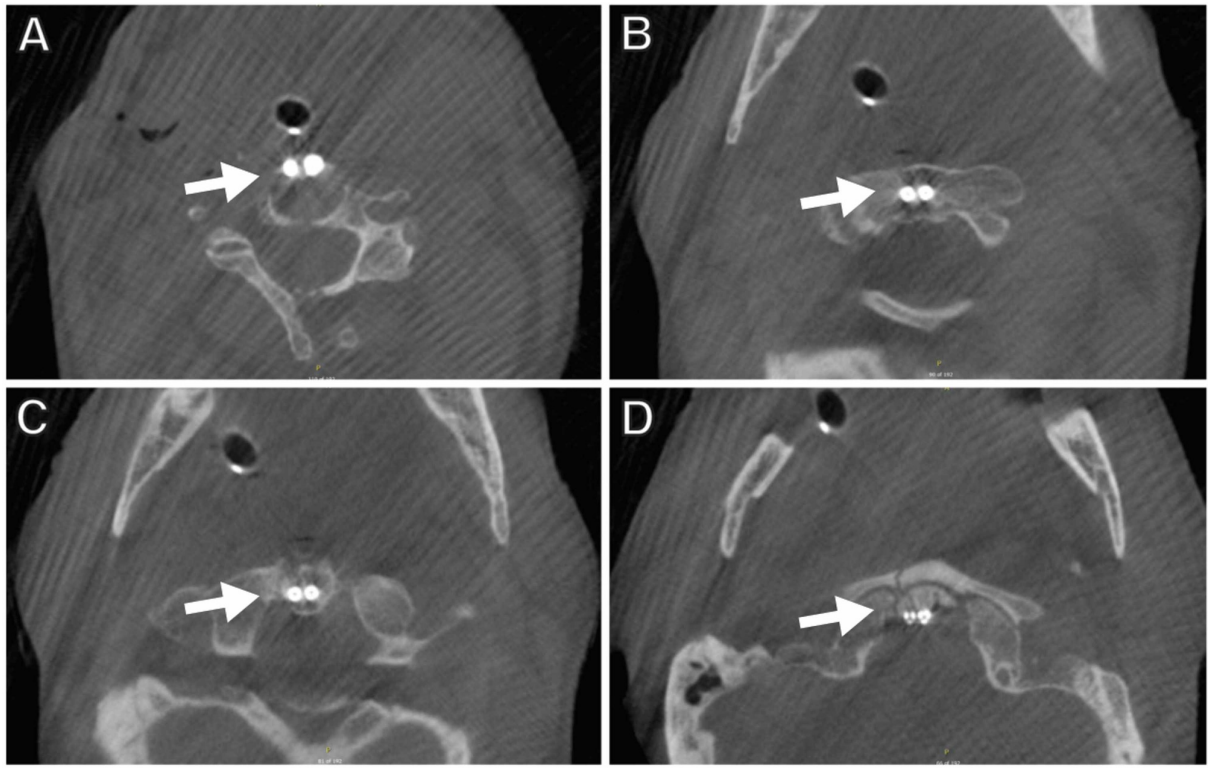

\section{FIGURE 4: Final intraoperative images}

The final CT spine confirms placement of the odontoid screws (indicated with arrows) from (A) the anterior endplate of $\mathrm{C} 2$, traversing the (B) $\mathrm{C} 2$ body and (C) base of the odontoid process, and (D) penetrating the cortex of the odontoid tip

CT: computed tomography

The patient recovered well and was discharged in good condition in a hard cervical collar. The X-rays obtained at the last follow-up demonstrated adequate fusion (Figure 5).
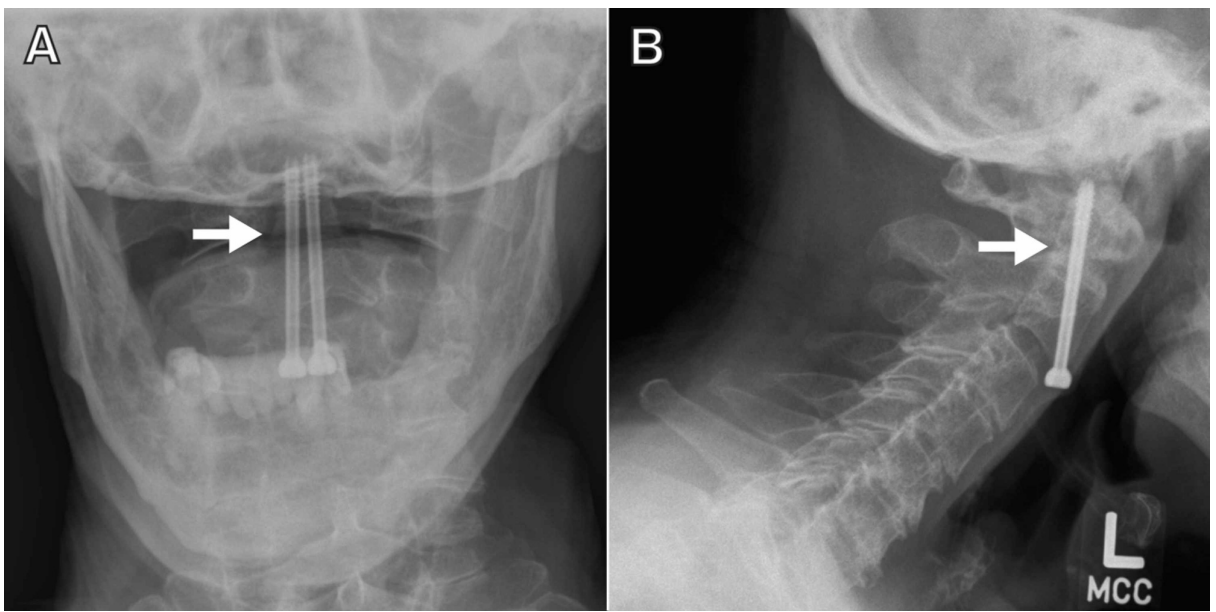

FIGURE 5: Three-month follow-up X-rays confirm healing of the fracture

(A) AP and (B) lateral views of the cervical spine demonstrating union across former fracture site (arrows)

AP: anteroposterior

Discussion 
Intraoperative navigation increases the accuracy of screw placement in spine surgery [7-9]. For example, Rajasekaran et al. demonstrated a significantly decreased rate of pedicle breach in thoracic pedicle screw placement when compared to non-navigated screw placement [9]. However, there are few reports of anterior odontoid screw placement using intraoperative navigation either with the O-arm or Iso-C systems [10-19]. Pisapia et al. recently compared outcomes for anterior odontoid screw fixation between navigated and nonnavigated cases using the $\mathrm{O}$-arm system. No malpositioned screws or neurovascular injury were reported although one patient in the navigated group had screw loosening and required posterior occipitocervical fusion [15]. Keskin et al. previously reported outcomes in 31 patients undergoing navigated anterior odontoid screw fixation using the Iso-C system. There were no malpositioned screws or neurovascular injury, although one patient required revision surgery due to non-union [13].

There are several advantages to using intraoperative navigation. An intraoperative CT provides a real-time view of the fracture and spinal alignment after the patient has been positioned. The CT is then used to plan and navigate the screw placement. In this case, we planned the placement of two odontoid screws to promote fusion, which is not feasible with standard biplanar fluoroscopy. Additionally, the built-in ability of the $\mathrm{O}$-arm to obtain $\mathrm{AP}$ and lateral X-rays eliminates the need for biplanar fluoroscopy and two C-arms. Finally, the ability to obtain a final intraoperative CT to confirm screw placement and fracture reduction allows confirmatory imaging before the patient leaves the operating room. The limitations include its size, expense, and radiation exposure to providers (although the latter can be avoided to some extent).

In this report, we demonstrated that the navigated placement of two odontoid screws can be safe and feasible in an octogenarian patient. As geriatric patients are at an increased risk for insufficient bony healing and non-union [20], we hypothesized that this approach would optimize fracture reduction and provide additional stability across the fracture, thereby increasing the likelihood of union.

\section{Conclusions}

The placement of anterior odontoid screws using the $\mathrm{O}$-arm navigation system is technically feasible and safe. The $\mathrm{O}$-arm provides real-time intraoperative anatomical visualization, including the fracture site and spinal alignment. In addition, the O-arm optimizes fracture reduction and screw placement. These factors allow for the placement of an additional screw, which may increase the likelihood of the union.

\section{Additional Information}

\section{Disclosures}

Human subjects: Consent was obtained by all participants in this study. Conflicts of interest: In compliance with the ICMJE uniform disclosure form, all authors declare the following: Payment/services info: All authors have declared that no financial support was received from any organization for the submitted work. Financial relationships: All authors have declared that they have no financial relationships at present or within the previous three years with any organizations that might have an interest in the submitted work. Other relationships: All authors have declared that there are no other relationships or activities that could appear to have influenced the submitted work.

\section{References}

1. Greene KA, Dickman CA, Marciano FF, Drabier JB, Hadley MN, Sonntag VK: Acute axis fractures. Analysis of management and outcome in 340 consecutive cases. Spine (Phila Pa 1976). 1997, 22:1843-1852. 10.1097/00007632-199708150-00009

2. Ryan MD, Henderson JJ: The epidemiology of fractures and fracture-dislocations of the cervical spine . Injury. 1992, 23:38-40. 10.1016/0020-1383(92)90123-a

3. Anderson LD, D'Alonzo RT: Fractures of the odontoid process of the axis . J Bone Joint Surg Am. 1974, 56:1663-1674.

4. Mummaneni PV, Haid RW: Atlantoaxial fixation: overview of all techniques . Neurol India. 2005, 53:408415. 10.4103/0028-3886.22606

5. Oertel MF, Hobart J, Stein M, Schreiber V, Scharbrodt W: Clinical and methodological precision of spinal navigation assisted by 3D intraoperative O-arm radiographic imaging. J Neurosurg Spine. 2011, 14:532-536. 10.3171/2010.10.SPINE091032

6. Silbermann J, Riese F, Allam Y, Reichert T, Koeppert H, Gutberlet M: Computer tomography assessment of pedicle screw placement in lumbar and sacral spine: comparison between free-hand and O-arm based navigation techniques. Eur Spine J. 2011, 20:875-881. 10.1007/s00586-010-1683-4

7. Guppy KH, Chakrabarti I, Banerjee A: The use of intraoperative navigation for complex upper cervical spine surgery. Neurosurg Focus. 2014, 36:E5. 10.3171/2014.1.FOCUS13514

8. Nakashima H, Sato K, Ando T, Inoh H, Nakamura H: Comparison of the percutaneous screw placement precision of isocentric C-arm 3-dimensional fluoroscopy-navigated pedicle screw implantation and conventional fluoroscopy method with minimally invasive surgery. J Spinal Disord Tech. 2009, 22:468-472. 10.1097/BSD.0b013e31819877c8

9. Rajasekaran S, Vidyadhara S, Ramesh P, Shetty AP: Randomized clinical study to compare the accuracy of navigated and non-navigated thoracic pedicle screws in deformity correction surgeries. Spine (Phila Pa 1976). 2007, 32:E56-E64. 10.1097/01.brs.0000252094.64857.ab

10. Ailawadhi P, Agrawal D, Satyarthee GD, Gupta D, Sinha S, Mahapatra AK: Use of O-arm for spinal surgery in 
academic institution in India: experience from JPN apex trauma centre. Neurol India. 2011, 59:590-593. 10.4103/0028-3886.84343

11. Costa F, Ortolina A, Attuati L, et al.: Management of C1-2 traumatic fractures using an intraoperative 3D imaging-based navigation system. J Neurosurg Spine. 2015, 22:128-133. 10.3171/2014.10.SPINE14122

12. Kantelhardt SR, Keric N, Giese A: Management of C2 fractures using Iso-C(3D) guidance: a single institution's experience. Acta Neurochir (Wien). 2012, 154:1781-1787. 10.1007/s00701-012-1443-9

13. Keskin F, Gomleksiz C, Sasani M, Oktenoglu T, Suzer T, Ozer AF: Clinical results of anterior odontoid screw fixation for Type II odontoid fractures. Turk Neurosurg. 2014, 24:750-756. 10.5137/1019-5149.JTN.981413.0

14. Martirosyan NL, Kalb S, Cavalcanti DD, Lochhead RA, Uschold TD, Loh A, Theodore N: Comparative analysis of isocentric 3-dimensional C-arm fluoroscopy and biplanar fluoroscopy for anterior screw fixation in odontoid fractures. J Spinal Disord Tech. 2013, 26:189-193. 10.1097/BSD.0b013e31823f62c7

15. Pisapia JM, Nayak NR, Salinas RD, et al.: Navigated odontoid screw placement using the O-arm: technical note and case series. J Neurosurg Spine. 2017, 26:10-18. 10.3171/2016.5.SPINE151412

16. Schouten R, Lee R, Boyd M: Intra-operative cone-beam CT (O-arm) and stereotactic navigation in acute spinal trauma surgery. J Clin Neurosci. 2012, 19:1137-1143. 10.1016/j.jocn.2012.01.020

17. Summers LE, Kouri JG, Yang M, Patrick Jacob R: Odontoid screw placement using Isocentric 3-dimensional C-arm fluoroscopy. J Spinal Disord Tech. 2008, 21:45-48. 10.1097/BSD.0b013e31805777da

18. Yang YL, Fu BS, Li RW, Smith PN, Mu WD, Li LX, Zhou DS: Anterior single screw fixation of odontoid fracture with intraoperative Iso-C 3-dimensional imaging. Eur Spine J. 2011, 20:1899-1907. 10.1007/s00586011-1860-0

19. Zou D, Zhang K, Ren Y, Wu Y, Yang Y, Li Y: Three-dimensional image navigation system-assisted anterior cervical screw fixation for treatment of acute odontoid fracture. Int J Clin Exp Med. 2014, 7:4332-4336.

20. Osti M, Philipp H, Meusburger B, Benedetto KP: Analysis of failure following anterior screw fixation of Type II odontoid fractures in geriatric patients. Eur Spine J. 2011, 20:1915-1920. 10.1007/s00586-011-1890-7 